\title{
Suzhi on the Move: Body, Place, and Power
}

Wanning Sun

During three months of fieldwork in Beijing in 2005, I rented an apartment in an eighteen-story residential compound (xiaoqu). On my first day, while waiting for the lift, I overheard two residents chatting. From what they were saying, I gathered that one of them was an information technology (IT) consultant. So while we traveled in the lift together, I asked him if he knew what I would need to do to access a local dial-up service. He gave me some advice, and I thanked him for doing so. But just before he stepped out of the lift, he turned and suddenly asked me, "Where do you come from?" Not wanting to hold up the lift for too long I gave him a short but true answer: I said I came from Anhui. He looked puzzled, "Are you for real?" "Yes, of course. Why do you ask?” I replied. "Well, I didn't think an Anhui person would need to know anything about Internet dial-up!" 
The meaningfulness of this exchange is not immediately apparent unless one is inducted into ways of decoding references to place and space in urban China. Anhui, as inscribed in the spatial imagination of urban residents in large Chinese cities, is not simply a geographic description of a particular place. Instead, the mere mention of "Anhui" mobilizes an array of stock metaphors, images, and stereotypes of rural poverty and backwardness. These metaphors, images, and stereotypes, which inform much of the popular representation, do not simply betray a set of views about Anhui held by people from more developed provinces - they are part and parcel of a hegemonic discourse based on a structural dichotomy between centers and peripheries, knower and known, and the independent and the dependent. ${ }^{1}$ This structurally unequal relationship determines that those from the "periphery" (such as less developed provinces like Anhui), once dislocated and moved to the "center" (such as a large metropolis like Beijing), become subalterns in the city, and almost by default acquire the status of having low suzhi (quality). As the other essays in this collection demonstrate, as a concept suzhi is highly mobile and seems capable of being deployed in almost any context in which comparisons between individuals, communities, and populations are being made regardless of gender, location, class, or ethnicity (or indeed because of them). An extremely resourceful term often used to decry a range of deficiencies from lack of formal schooling and low literacy to poor personal hygiene and table manners, suzhi is commonly found lacking in people who migrate from poorer, interior provinces such as Anhui to the wealthier metropolises and industrial centers on the coast. Such migrants come from a variety of backgrounds and include some wellto-do and highly educated urban professionals and businesspeople, but once in their place of destination, all are marked by the stereotype of the migrant as a rural, poor, lower-class laborer, lacking in suzhi. And, to take this cultural logic one step further and understand my IT neighbor's surprise at my question, since migrants from Anhui have low suzhi, they are unlikely to be in want or need of Internet access.

Since the migrant body refuses to be bound to the place of origin and prefers to infiltrate the habitat of the urban resident, the cultural politics of boundary keeping must (re)inscribe place onto the mobile body. This boundary maintenance necessarily relies on a semiotic skill of reading what I call 
the "corporeal evidence" — the complexion, hairstyle, accent, speech, body language, and, by extension, clothes of the mobile body. In the case of the IT consultant, it is likely that his wondering where I came from stemmed from a desire to "read" me as a somewhat confusing corporeal text. On the one hand, I dressed and looked like the Anhui people in the building who worked as maids and cleaners. On the other hand, I did not have an easily identifiable Anhui accent, nor did my technologically oriented question conform to his idea of the suzhi level demonstrated by a "typical" Anhui person, such as a maid or cleaner.

Deploying a Marxist notion of value, Yan Hairong argues that suzhi is a value articulation of human subjectivity and that it has gone through a process of valorization and fetishization. ${ }^{2}$ This process, she goes on to demonstrate, subsumes human subjectivity, which is heterogeneous and individual, to the discourse of development, which is abstract and universal. In addition, she argues that the post-Mao cultural production of the concept of suzhi is crucial to the economic production of surplus value extracted from rural migrant workers, as suzhi functions as an "intangible operator" in the labor contract. Suzhi discourse, Yan argues, is central to a neoliberal governmentality, as the domination of suzhi "facilitates exploitation and makes it invisible." 3 Furthermore, it functions as a technology of the self through which, in order not to fall into "abjecthood," migrant women engage in "self-development" of a kind that further contributes to the production of surplus value. ${ }^{4}$

In an analysis similar to that of Yan Hairong, also inspired by Gayatri Chakravorty Spivak and a "poststructuralist reading of Marx's concept of value," Ann Anagnost pits the body of the rural migrant against that of the urban, middle-class only child. ${ }^{5}$ In doing so, Anagnost is able to show that suzhi not only codes the difference between these two social groups but also suggests strategies for the social mobility of each. She argues that suzhi is both an ideological formation and corporeal politics, since the power of suzhi derogates migrant bodies and allows the "transfer of surplus value from one body to another." Furthermore, Anagnost points out that suzhi yields surplus value not only in economic terms but also in terms of political representation, as it "works ideologically as a regime of representation through which subjects recognize their positions within the larger social order." 
Yan and Anagnost's determination to give material expression to a highly abstract concept via the migrant body is both illuminating and innovative. Both introduce a spatial dimension to the discussion of class formation. Both point to the "phantom-like" quality or the "insubstantiality" of suzhi discourse but argue that it is precisely this lack of semantic specificity that lends it potency and power and allows a process of fetishization to occur. Linking suzhi with the social mobility of social classes, they describe a rural migrant that embodies surplus value through his or her lack of suzhi. However, in their efforts to decode the operation of suzhi in relation to the migrant and the middle-class "only child" (dusheng zinü), both go no further than to deploy a simple rural/urban dichotomy, leaving other crucial geographical and spatial markers of difference largely unaccounted for. In the geography of imagination in reform China, these markers can include North versus South, inland versus coast, and big metropolis versus medium or small cities. Also ghostly yet equally powerful is the often-deployed distinction between waidiren (outsiders) and bendiren (local people). While Yan and Anagnost's linkage of value with suzhi via the rural/urban dichotomy may help explain why urban and middle-class families may be able to afford to employ rural migrants as baomu, and while it may also help explain why rural migrant baomu in large metropolises such as Beijing and Shanghai earn less than their local counterparts, it nevertheless does not explain why, for example, Beijing residents are willing to pay a bit more for a baomu from Sichuan than for one from Anhui. Nor can it answer the question as to why most baomu are identified, by their employers and their own peers, not as "rural" or "urban" but as baomu from a certain region, town, or province.

In this essay, I want to build upon Yan and Anagnost's discussions of suzhi and corporeal politics, extending the analysis in two different directions. First, I want to raise further questions about the processes through which suzhi "derogates" the migrant body and allows the transfer of surplus value from one body to another. More specifically, I wish to consider the form and shape the derogation of the body takes in the everyday life of a migrant worker. Second, by considering a number of ways in which the migrant body is used as a signifier of subalternity, I wish to extend the analysis of how spatial markers of difference operate in discourses on suzhi and migrants. I shall pursue both these objectives by focusing specifically on 
migrant women working as baomu. ${ }^{6}$ Paid domestic work, a line of employment which has reemerged in urban China since the economic reforms began in the late I970s, has become an increasingly common commodity. A growing number of households in urban areas are in need of and can afford to employ domestic help. For a rural woman migrant leaving the village to seek income in the city, becoming a domestic worker is a realistic employment option. Yet what seems to be the "easiest" job possible for a village woman — cleaning, caring, babysitting, and cooking — often proves to be fraught with disappointment, frustrations, and challenges, both for domestic workers themselves and for the city residents who employ them. This is because, on the one hand (rural) women, rather than men, can be marketed as good baomu, since women are generally regarded as more natural and better carers. On the other hand, domestic service is believed to be most suitable for rural women, as it is both low-status and low-skilled work. The fact that baomu are primarily female from rural areas - and therefore of supposedly low suzhi - is a key factor contributing to their low status and vulnerability to exploitation, abuse, and objectification. ${ }^{7}$ The focus on rural migrant women who work as baomu therefore presents a good point of entry to consider how gender intersects with place and class in suzhi discourse.

The fieldwork on which this essay is based consisted of several short trips to Anhui and Shanghai from 2002 to 2004 and a three-month residence in a xiaoqu (residential community) in Chaoyang District, Beijing, in the summer of 2005. Data comes from both informal conversations and interaction with a number of domestic workers, as well as interviews with employers, domestic service agents, staff working at various recruitment and training centers in Beijing, and supporting groups and organizations for migrant women.

\section{Histories of Prejudice and Place}

Prejudice against people based on their place of origin is not unique to the post-Mao reform era. Emily Honig's discussion of the discriminatory treatment of Subei people (people from northern Jiangsu Province) by Shanghai residents toward the end of the nineteenth century and throughout the twentieth $^{8}$ points to the complex intersection of class, ethnicity, and native place 
identity. As Honig's work demonstrates, migrants from northern Jiangsu, because of their marginal socioeconomic status - they mostly worked as cobblers, barbers, rickshaw pullers, and prostitutes - came to signify the other within the metropolis of Shanghai. It is also important to recognize that place-based stereotypes are not unchanging and are in fact subject to economic growth and the evolving power dynamics between regions and places. While Anhui people in recent decades have been associated with poverty, backwardness, and low suzhi, in late imperial times Anhui produced merchants who were known throughout the empire as culturally cultivated, ethical, and entrepreneurial people. ${ }^{9}$

The practice of place-branding is rooted in China's long-standing and deeply entrenched hukou (household registration) system, which was introduced in the I950s. This system effectively differentiates the population along urban-rural lines, continuing to do so even after changes of recent decades that have made it easier for rural residents to enter the cities in search of work. Although both the state and the market recognize that the labor of rural migrants has become essential in urban China, and have encouraged and facilitated their entry into the city through a series of reforms to the hukou system, they have by no means eradicated discrimination against the rural population. According to Wang Fei-ling, "interregional migration and population mobility are controlled and regulated; people's rights and opportunities are different according to where they are registered, despite the fact that the interregional borders are open to travelers." 10 In other words, the hukou system continues to prevent the majority of rural migrants from claiming a entire range of entitlements, including education, housing, job opportunities, and medical care. ${ }^{11}$ It has also given rise to myriad ways in which the "other" and "outsiders" are imagined, thought of, and talked about. One central aim of this essay is to demonstrate that although reform of the hukou system has relaxed its "rigidity" and "diminished its discriminatory impact" in the material sense, ${ }^{12}$ such change has in fact given rise to a greater need for exclusion and boundary keeping at a symbolic level, hence the need for branding people in terms of place of origin. 
In my open-ended conversations with more than a dozen employers of baomu, both men and women, in various Chinese cities, suzhi unfailingly came up as the reason for their unsatisfactory performance. When I asked them to define what suzhi consists of, they usually fell back on examples that were illustrative of low suzhi. One employer said that her maid ate noisily and complained, "That's not good for the manners of my child." Another complained that her maid often forgot to close the bathroom door when using the toilet. A female employer of two rural cleaners told me that good suzhi also means good qizhi (style of carrying oneself). According to her, her cleaners were te tu (really rustic); "They are not very bright" [bu lin qi]; and "They are slow and unresponsive [chi dun], wooden [dai dai de], not sure what to do yet too timid to ask." ${ }^{13}$ Media stories often carry employers' gripes about their unhygienic maids, who, for example, smell of garlic, lick the mouth of the sesame oil bottle while making salad dressing, feed a child with the food chewed and taken from their own mouth, or inappropriately handle the pointy end of chopsticks with hands while setting the table. ${ }^{14}$ While baomu are employed to routinely clean various kinds of bodily fluids of the person they care for, especially young children, the old, and the bedridden, they are themselves expected to have a closed body, free from odors and fluids and the reality of their bodily functions. There is great irony in this: while the reality of the abject body is the very reason why a carer is required, the carer's own body, in order to be seen to have good suzhi, has to be clean, free of unwanted odors and fluid, or, to use Julia Kristeva's term, "sublime." 15

Efforts to cleanse the migrant body of rurality are made at both individual and collective levels. Pun Ngai finds that a global factory in Shenzhen implements a wide range of techniques of discipline, ranging from spatial practices on the assembly line to timetabling aimed at transforming dagong$m e i$ from rural laborers to industrial workers. ${ }^{16}$ In the case of baomu, teaching materials universally put an emphasis on the need for prospective baomu to change their rural habits and adapt to the urban way of life as quickly as possible. For example, the Ministry of Labor and Social Security has written a series of handbooks for training baomu ${ }^{17}$ According to these handbooks, 
prospective baomu need to learn how to sit, stand, and walk properly; must learn that in the presence of others they should not, for instance, comb or shake their hair, pick their nose or ears, cut their nostril hair, scratch themselves, or shake their legs; and must remember to cover their mouth with a tissue or handkerchief when sneezing or blowing their nose, and to say "Excuse me."18

One must remember that the urban, middle-class only child and the migrant body that Anagnost pits against each other do not live in independent universes. In the case of the baomu and the child - or, for that matter, the baomu and the elderly person she looks after — the labor of caring takes the form of one party giving direct bodily and physical care to the other. After all, it is the baomu's hand that puts food in the child's mouth, cleans up the dirt he or she leaves, and wipes excrement from his or her anus. It is in this kind of quotidian and repetitive physical contact and interaction between the giver and the taker of care that the power dynamics between the rural migrant and her employer (both adult and child) are set and negotiated. Suzhi discourse operates at the corporeal level, not just because in theoretical terms it allows the value of one body to be transferred to the other, but more tangibly because it is embedded in an entire array of bodily practices including the following: what bodily smells, touch, and physical bearings are (un)acceptable in daily interaction; whose bodies are seen to be in need of being regulated, managed, and sanitized; and whose rules of bodily contact are dominating. The body functions as a way of regulating class-based difference, anxiety, and desire, allowing the urban middle class to claim superiority to its rural, peasant, or working-class other.

Unbeknownst to rural migrants, when they leave the village, enter the city, and walk into urban residents' home as baomu, their place of origin has already been abstracted into a signifier of rurality and low suzhi which, against their wishes, is reinscribed onto their mobile body. As Louisa Schein suggests, places are constituted "not only . . by their location and physical features," but also by the "specific, often regulated, forms of bodies that inhabit them." 19 "Bodies," she observes, "can serve as dislocated signifiers of place."20

A couple of examples may illustrate how the migrant body functions as a dislocated signifier of place. A few years ago, a job center in Shenzhen adver- 
tised for two company security guards. The advertisement clearly stated that "applicants from Henan and Anhui Provinces need not apply." Sensing a potential controversy, a Shenzhen Business Daily journalist interviewed the manager, who justified his place-based criteria this way:

Workers from some provinces have low suzhi. If an enterprise employs too many people from one particular province, the old thoughts and values brought from home by these people will find new soil in which to live. If an enterprise makes a point of recruiting people from different places, their values and practices will come into conflict. In the long run, this will help them grow, and it is also good for the development and management of the enterprise. I hope people will understand the intention of our advertisement in this light. ${ }^{21}$

Although assumptions made about the people from other places fall into the category of urban myths and are intelligible only to those who are literate in the idiom of the popular place-imaginary, they are not outside the political economy of suzhi discourse, in which the state is a crucial player. In April 2005, a lawsuit — the first of its kind — was lodged against a branch of Shenzhen's Public Security Bureau (the equivalent of the Chinese police force). After seeing displayed in prominent public spaces a banner that said, "We will firmly crack down on the swindlers' clique from Henan [Province]," two individuals from Henan took the local police to court for place-based discrimination and demanded that a public apology be published in the national state-run media. ${ }^{22}$ Both of these examples point to the ironic effect of being mobile: Most rural migrant women leave home to escape the fate of being rural, as they see going to the city as the only way to escape what Yan Hairong calls the "symbolic field of death." 23 Yet as it turns out, their mobility does not necessarily help them shed rurality. Instead, once in an urban environment they become more "rural," less "civilized," and are seen to be bereft of suzhi. Clearly, rural workers from Henan and Anhui, though physically dislocated from their place of origin, continue to embody rurality and lack of suzhi for many urbanites, including employers and state officials, although it is also clear that such stereotyping does not go uncontested.

The signification of otherness and low suzhi through the migrant body is doubly punitive if the migrant body also happens to be female: Chinese 
family life conspires with the rural-urban divide to produce a strong desire to leave the village home to engage in manual labor, but at the same time, women are more prone to both patriarchal practices at home and genderand place-based discrimination in the workplace. On the one hand, global capital relies on the cheap labor of female rural labor forces. On the other, most of these factories adopt an explicit place-based policy of recruitment, preferring Guangdong women over those from northern and inland China. ${ }^{24}$ Similarly, in the baomu industry, while the city depends on the continuous supply of fresh recruits from rural areas, and while rural women are encouraged to join the baomu profession, as it is supposedly the most realistic and viable job for a rural woman, the industry also nevertheless unapologetically favors local, southern, and ultimately urban baomu women over waidi, northern, and rural women.

\section{Rural/Urban Differentiation}

In the baomu industry, as in many other contexts, the suzhi discourse is continually deployed by employers and domestic service agencies to comment on and deplore the (lack of) "quality" of domestic workers, who are seen to therefore be in need of management, discipline, and control. Why is this assertion — that baomu lack suzhi — so frequently repeated, given that it is also deemed to be so obvious and inevitable? Is it because urban residents, while astute consumers of cars and houses, have yet to learn the correct way of consuming human labor? Zhang Xianmin, the general manager of the March 8th Domestic Service Center, the longest and most established center in Beijing, believes this to be the case:

Our clients [i.e., employers of baomu] may make the most informed decision about which restaurants to go to in order to entertain which kind of guests in order to make the most appropriate impression or signal the most appropriate level of hospitality, but when it comes to hiring a baomu, they are usually not that smart; they want to pay minimum wages to their baomu but still expect fine cuisine on their dinner table every day. ${ }^{25}$

Contrary to Zhang Xianmin's observation, I suggest that the perennial chorus of "no suzhi" or "low suzhi" from baomu agencies and employers 
makes a great deal of business sense. Suzhi discourse is not only politically useful but also economically rational: it enhances the sustainability of a supply of cheap labor. What the industry and employers of baomu are reluctant to acknowledge is the fact that paid domestic work has become an affordable consumption item for many urban residents precisely because rural women are perceived to have low suzhi. In other words, thanks to the suzhi discourse, which functions as (in Yan Hairong's words) an "intangible operator," rural women - who are presumed to lack suzhi and who constitute about 8 o percent of the domestic work workforce — can be expected to be not only docile and manageable, but also easily available and affordable.

The repetition of suzhi discourse also contributes to the maintenance of urban status and identities. For urban employers of baomu, this is particularly important, since the baomu's residence in their most intimate home-space poses an especially serious threat to urban notions of distinction from, and superiority over, the rural. The "low-suzhi" baomu body has thus become the site whereby rural-urban difference is (re)marked, urban sense of superiority (re)affirmed, and urbanites' right of access to cheap labor assured and asserted.

Feng Xiaoshuang, a sociologist in Beijing who has written on employerbaomu relationships, finds that both employers and baomu tend to attribute good qualities to individuals but to blame the place or environment if the quality is unfavorable. ${ }^{26}$ For instance, favorable comments such as "My employer is the best person in the world" or "My baomu is the most hard-working person you can ever hope for" focus on the person concerned, whereas unfavorable comments such as "They borrow money but never return it. Typical country people," or "They smile at you even though they are ripping you off. That's city folk for you!" highlight the individual's place of origin. This tendency to rationalize the lack of suzhi by resorting to spatial categorization is so strong, argues Feng, that the rural-urban duality can operate as a default code one can use to decipher the most complex and fraught relationship between employer and baomu. Feng concludes, "Any attempt to account for the complex employer-baomu relationship outside this rural-urban framework is ineffectual and is little more than wordplay."27

By the same token, rural-urban difference is also an enabling framework for those many defenders and apologists for baomu accused of having low 
suzhi. To them, employers' complaints about their employees' low suzhi do not automatically elevate the employer to the status of having suzhi. Rather, it reflects the urban residents' ignorance of social and cultural conditions in rural China. According to Xie Lihua, "many of the employers have never been to the countryside and have little or no knowledge of the discrepancy between the city and country. Nor do they bother to learn about the living standards and ways of life that their baomu are accustomed to. So of course they will be in for a rude shock when a rural baomu arrives in their home." 28 Zhang Xianmin, quoted above, echoes this view:

Our clients [employers of baomu] are disappointed when they find that their baomu cannot cook meals to meet their standard. They also feel cheated, as they asked their baomu during the interview if she can cook and received a positive reply. She was not lying. She can really cook, and has been cooking all her life for her family. But city folks take their living standards for granted. It never occurs to prospective employers that city people have different expectations from country people. ${ }^{29}$

Stella Xing, the head of Fuping Domestic Service, one of the biggest and most well-established domestic service training and employment centers in Beijing, provided me with a telling example of how easy it is to blame a baomu for her lack of suzhi when in fact it is the employers' lack of understanding of rural life and their inability to negotiate cultural differences with their baomu that is at fault. ${ }^{30}$ According to one of her clients, the baomu went along with the family for a meal in a restaurant. Among several dishes ordered to the table was a dish of king-sized prawns. While the family members were holding back from taking their share of this expensive delicacy, the baomu put all the prawns on her plate — obviously "selfish," "inconsiderate," and unacceptable behavior from her employers' point of view. When the agency received a complaint and stepped in to mediate, it became clear that the baomu, who came from a rural area in a northern inland province, had never seen prawns and had no idea of their worth. She thought she was doing the family a favor by eating their leftovers! While such a story can be (and often is) recounted by employers and urban residents to illustrate the maid's parochialism, it is told here as a story of misunderstanding for which urban residents are equally responsible. 


\section{Outsider versus Local}

Yan Hairong, one of the few scholars outside China to have done research on baomu, believes that the "specter of class" haunts the employer-maid relationship. Feng Xiaoshuang, by contrast, argues that rural-urban difference offers a more effective framework for understanding the employer-maid relationship than class difference does. For Feng, a semiotic of place and space, rather than class, is the key to understanding the discursive formation of suzhi discourse. ${ }^{31}$ I want to suggest that neither class nor place-based difference alone is adequate. Instead, class and place need to be considered as intersecting and mutually constitutive. Thus, urban understandings of low suzhi, of "marginal places," of rurality and of the peasant and working classes, feed upon and reinforce one another. Consequently, all peasants are assumed to be lacking in suzhi, and anyone from "the periphery" is viewed as peasantlike (if not an actual peasant) and therefore lacking in suzhi. This is what accounts for the IT consultant's inability, as recounted at the beginning of this essay, to reconcile my place of origin (Anhui) with my technologically oriented question.

In addition, in order to effectively unravel the operations of suzhi discourse in the employer-maid relationship, we must move beyond a simple rural-urban duality to consider a range of spatial categories and distinctions. To start with, aside from the rural-versus-urban distinction, a divide between locals (bendiren) and outsiders (waidiren) is also an important consideration in urbanites' recruitment, management of, and daily interaction with baomu. Presented with a prospective waidi baomu by a domestic service agency, employers usually feel that there is little they can do to assure themselves that this "outsider" is reliable and trustworthy. This distrust and anxiety come not so much from contempt for country people as from a fear of rootlessness. Many employers use the term zhi geng zhi di (knowing one's roots and one's background) to justify their preference for local baomu and local part-time cleaners. "Sure, a waidiren can show me her identity card, but I have no way of knowing if the card is fake," one employer says. "What if she runs away with my baby? I have no way of tracking her down," Xie, a young mother of a five-month-old tells me. ${ }^{32}$ "I trust my cleaner and leave my keys with her so I don't have to be home when she cleans. I can do 
so only because she is a local Beijinger. There is no way I will leave my keys with a waidiren. Absolutely not!" says Shen, a PR consultant in Beijing who has his upmarket apartment cleaned once a week. 33 The desire for the territorial fixity of the maid and for the protection of the employer's private and personal space explains why local part-time cleaners - often laid-off factory workers - are more sought after and command the highest rate in the baomu market. It also explains why relatives - often many times removed - from the nearby rural counties, such as those on the outskirts of Shanghai or Beijing, are considered to be most desirable, as they are, on the one hand, affordable due to their rural status, and, on the other hand, locatable and thus safer.

The paradox of mobility and power is such that for the wealthy and the middle class deterritoriality is a sign of a superior cosmopolitan nomadism and freedom, but for the working class it is associated with vagrancy. ${ }^{34}$ For instance, Sylvie $\mathrm{Xu}$, a Shanghai resident, is highly cosmopolitan. She lived in France for ten years and came back to Shanghai a few years ago. She now works as a scientist in a French-owned pharmaceutical company in Shanghai and travels to France at least twice a year. She speaks fluent French and is taking lessons to improve her English, but although she is a native of Shanghai, she speaks Mandarin most of the time. Xu has a local maid, as do most of her friends. Local maids command a higher price, because they are not as easily available as Anhui maids. According to Xu there are several reasons for this discrepancy. Local maids tend to be laid-off factory workers. For them, becoming a maid is a big step down in status and hence is usually perceived as a last resort. Such women are more desirable as maids because, according to $\mathrm{Xu}$, they tend to be older, more responsible, and more experienced with household work, including child care. They are also thought to be more capable of modern household tasks such as operating an automatic washing machine or programming a microwave. According to $\mathrm{Xu}$, local Shanghai maids are also preferable because of their "locatability" or "localness." Waidi maids come from somewhere else, have no fixed address, and can leave without a trace. Xu mentioned that stories of maids from outside Shanghai stealing or "ripping off" employers and then "doing a runner" are widely circulated. By contrast, local maids are bona fide residents and therefore are zhi geng zhi di. ${ }^{35}$ 
It is not just urban elites who decry the unreliability and low suzhi of waidiren. Some marginalized city people, such as laid-off workers, also complain about the low suzhi of waidiren as a way of accounting for their own unsatisfactory situation - placing blame on the outsiders who have taken their jobs - or in order to claim an innate place-based superiority despite their own marginal position. Ge Xiuying, a forty-seven-year-old former factory worker now working as a maid for an Australian family in Shanghai, may well be one of these people. Ge, a second-generation Shanghainese, has never lived outside Shanghai. She graduated from high school in 1974 and was fortunate enough to escape being sent down to the countryside. Her experience with non-Shanghai places included a brief sightseeing tour to some of the cities adjacent to Shanghai, including Nanjing, Hangzhou, and Wuxi. Ge has had little contact with waidiren and does not have a very favorable view of them. "Most of the maids in Shanghai are waidiren. They are cheaper to employ. Most of them are poorly educated, so they are usually hired by people who have an ordinary job [gong xin jie ceng].” By contrast, she said, "white-collar professionals who work in foreign companies [bai ling] have much higher expectations" (that is, they engage local Shanghainese women as maids). Ge further suggested that once one reaches the echelon of "white-collar professionals working in foreign companies" one's waidi status becomes irrelevant. Ge's employer, for instance, is a Chinese migrant with Australian nationality now working for a transnational company in Shanghai. In spite of the fact that he is a Henan native, in his maid's imagination his waidi status has clearly been eclipsed by a Western and, by implication, more modern status.

Ge also believed most waidi maids had little education and knowledge about the law. She recounted to me a story she watched on television about an older maid from Anhui Province who, trying to kill the younger maid with rat poison for reasons of jealousy, ended up killing the young child of the employer by mistake. "Imagine that! She is blind to the law [fa mang]!"36 It seems clear from Ge's case that the trope of "outsideness" in suzhi discourse is available not only to employers of baomu but also to local baomu who consider themselves superior to baomu from elsewhere. In both cases, it works to mark out the boundary between self and other, and it does so by conflating a spatially based hierarchy with a morally based one. The migrant 
who works as a maid is perceived to have low suzhi not only because she is seen to lack civility and modernity but also, equally important, because she is mobile and "floating" - her rootlessness and her "out-of-placeness" associate her, as Li Zhang demonstrates, with moral deficiency, and in some cases even with criminality. ${ }^{37}$ Ge's confidence in commenting on the low suzhi and, hence, inferiority of the waidi maid remains undiminished in spite of her own occupation as a "lowly" maid. This is because being a Shanghai native gives her the "natural" and unquestionable right to claim a sense of belonging in the city. Her status as a native is the very stuff out of which social and cultural capital is made.

My conversations with employers in Beijing, Shanghai, and mediumand small-sized cities in Anhui all suggest that waidi and bendi are powerful signs in the social semiotics of place and space. In fact, these categories sometimes even override the rural-urban demarcation. To be sure, rurality is usually blamed for lack of civility, manners, hygienic habits, and scientific knowledge of housekeeping, but it is the outsider status of the maid that most commonly triggers urban anxieties about children being abducted, money stolen, and elderly people being abused. This is why some urbanites feel safer engaging relatives from rural areas as maids or recruiting rural maids through "word of mouth" rather than "blindly" hiring unknown maids from the countryside.

\section{Sichuan Mei versus Gansu Mei}

Besides the rural-urban distinction discussed by Yan Hairong and others, and the waidi-bendi demarcations discussed so far in this essay, regional differentiation and branding also characterize discourse on migrants. In fact, branding people according to place of origin is a practice common to employers and employees alike. Place-based people-branding has become a product differentiation technique and a marketing strategy, and the success of this strategy lies in conflating place with body. In no other profession is this more apparent and taken for granted than the domestic service industry. In December 2003, an application to register Sichuan mei (Sichuan girls) as a product logo was lodged with China's Industry and Trade Bureau, and by the end of 2004 the logo was officially approved. ${ }^{38}$ When 
I asked some employers why Sichuan mei was a good brand, their replies invariably contributed to place-making. Employers told me that "Sichuan mei are hard-working [neng chi ku - literally, "able to eat bitterness"], as they tend to come from poor areas"; "they have clean habits, as water is plentiful where they come from"; and "they are good cooks, as their main diet is rice and they know how to cook tasty dishes to go with rice." They are also known to have "gentle southern accents" and "attractive looks." It is indeed the case that "bodies are not simply in places; bodies are places." 39 According to Stella Xing, who routinely fields requests for maids, prospective employers often ask for maids from a certain region. Understandably, some request a woman from the same region or province as themselves so that there will be minimum conflict of habits and customs. However, many people, including northerners, request "southern" maids — usually referring to those from Jiangsu, Anhui, and Sichuan - and implicitly reject "northern" maids, those who come from, for instance, Gansu, which has now become the largest source of supply of domestic workers in Beijing. According to Xing, "southerners are believed to be more hygienic. There is more water in the south, so people wash more." As if to reinforce the validity of this view, a staff member at the same agency told the anecdote of a Gansu maid who not had a shower for a fortnight since starting to work for a Beijing employer. When questioned, the maid said, "I already had a shower, just before I came here." Clearly, in this case what is problematic about the Gansu maid is not her rurality or outside-ness but her northern-ness and inland-ness: Gansu is a dry province, and its water shortage has given rise to water-saving habits that are unacceptable to Beijing residents. The juxtaposition of Beijing consumers' different perceptions of Sichuan mei - who have "southern bodies" - and domestic workers from Gansu - who have "northern bodies" - gives a concrete illustration of what geographers have always told us: it is not only that "places shape bodies"; it is also, and just as important, that "bodies index places." ${ }^{40}$ In other words, the relative marketability of Sichuan maids compared to Gansu or Anhui maids may be a result of marketing strategy, place-branding, and the specific patterns of migration to Beijing. It may not be so much a reflection of China's increasingly deterritorialized cheap labor force, as is the case with industrial labor, or of the amount of suzhi possessed by individuals from these places. 
Province is the most common category of place with which baomu are described and appraised, even though they themselves may not regard "province" as a strong form of identity. Thus, although domestic workers may come from various counties or towns in Sichuan (e.g., Leshan, Xin Wen, or Jiang You), they are usually simply referred to as Sichuan mei or chuan mei zi (Sichuan girls), even though the province of Sichuan - like Anhui, and Gansu too for that matter - is very large and encompasses a huge diversity of dialects, customs, and mentalities. Among the numerous domestic workers from Sichuan I met during my residence in Beijing in 2005, many told me that they do not necessarily relate to people from Sichuan as lao xiang (people from the same native place) unless they are from the same county or can converse in each other's dialect. The tag of "Sichuan," "Anhui," or "Gansu" is imposed on the domestic worker whether or not she finds it useful or relevant.

I would argue that such tagging has a number of unfortunate ramifications. First, it works to mark the outside-ness of the migrant body in question, thus reterritorializing her. Second, by lumping individuals together with a label of a particular province, this practice rules out the specific claim to suzhi that individuals may otherwise have depending on background and life experience. For instance, Xu Xiuying, a part-time cleaner from Henan whom I interviewed, is painfully aware of the power of popular place imagery and the disadvantage of not belonging to a sought-after brand:

Many people ask me where I come from, and I notice that it's often a conversation stopper when I tell them the truth. So once, when I went to clean for a new client and he asked me this question, I said that I come from He Ze, Shandong Province - a fellow cleaner comes from there, so I know the name of the place. He was quite happy with my cleaning and said, "You have done a good job. No wonder Shandong people have the reputation of being honest and hard-working." I then smiled at him and said, "Actually I am from Henan, so you'd better check to see if anything is missing in the apartment before I leave!"41

Third, once established, these tags are sometimes embraced by sending zones, which in turn internalize the receiving zones' hegemonic assumptions of place. For example, an article published in a metropolitan newspa- 
per in Sichuan sounded an alarm bell to all Sichuan compatriots, cautioning readers that Sichuan should not be too complacent with its chuan mei zi product. According to the story, the reputation of the chuan mei zi may have been somewhat tarnished in Beijing because of "pirated copies [daoban] of chuan mei zi hitting the black market" and "counterfeit Sichuan maids taking employers for a ride." An employer in Beijing is quoted in the story as complaining that she specifically requested a chuan mei $z i$ and assumed that she had secured a Sichuan girl based on her accent. After a few weeks, she became suspicious of the maid's authenticity: "In my imagination, Sichuan $m e i$ are clever, competent, and hard-working, but this baomu is nothing like that. So I asked to check her papers only to realize that she comes from a province next to Sichuan!" The story cautions employers not to trust baomu self-advertising on the black market: "Many girls roam around on the 'black' job market, some with notes on their body specifying their special skills. When prospective employers approach them, many introduce themselves as chuan mei zi." 42 These statements assume the superiority of Sichuan mei as a given, and clearly they are made to mark the difference between Sichuan Province and less "desirable" provinces. They are problematic in that they commodify and objectify women by implicitly referring to them as tu techan - indigenous products of a particular place, similar to "Shaoxing wine” or "Qingdao beer." Described as baomu from a certain province, women are presented to urban residents not as individual human beings but as a new consumer experience, similar to tasting the first batch of the season's fresh vegetables. As one commentator for the Elite Shoppers' Guide to Luxury Goods put it:

Beijing shoppers are tired of consuming the same brands in the same old fashion. They are looking for new ways of consuming. "Tasting freshness" [chang xian] is one of them. Cucumbers, for instance, are good only in early spring, especially those young tender ones with tiny spikes. After that, any other cucumbers are pretty ordinary. . . . How about trying freshness of another kind? Try a new baomu wearing the "Sichuan mei" logo. A new batch has just arrived, all wearing pretty pink uniforms! ${ }^{43}$ 


\section{The Baomu as Symbolic Border Guard}

While the baomu market in Beijing and other metropolises is dominated by waidi baomu, most of whom are of rural origin, ${ }^{44}$ in the I99os, local residents also began working as baomu, although the number was still very low. ${ }^{45}$ Given the intense collective effort to urbanize rural domestic workers, and given the palpable anxiety caused by rootless waidi baomu, one could be forgiven for assuming that the small number of local urban baomu have unrivalled competitive advantage over their rural and waidi counterparts. But this is not always the case. According to a survey conducted by a domestic service agency in Beijing's Haidian District in the late I99os, the majority of respondents preferred waidi baomu over Beijing baomu. ${ }^{46}$ To be sure, Beijing baomu were thought to have compatible lifestyles with employers and to know the do's and don'ts of urban etiquette and were believed to be zhi geng zhi di and thus more likely to give employers peace of mind. However, they were also known to be more "difficult to boss around" (bu hao zhi shi), to "know too much," and to be "prone to gossip." ${ }^{47}$ My interviews with industry spokespeople echo this perception. Zhang Xianmin, manager of the March 8th Domestic Service Center, believes that Beijing baomu are too "proud" and tend to behave like bosses rather than employees, having been brought up "right next to the imperial palace [huang cheng geng xia]." ${ }^{8}$ Similarly, Stella Xing commented that Beijing people, even baomu, thought they were "born to rule." 49

What does some urban employers' preference for rural, waidi baomu, despite their "low-suzhi" reputation, teach us about consumption? I suggest that the domestic worker's body is the site of political and economic negotiation, where a compromise is sought between the woman's market value, based on her place of origin and other attributes, and the effectiveness with which she functions as a "symbolic bodyguard" between "here" and "there," between "us" and "them." ${ }^{0}$ In other words, whether to hire a waidi baomu, a rural baomu, or a local urban baomu is determined not just by her use value but also, equally importantly, by her symbolic value. In Beijing, local baomu may be considered more competent and reliable, and thus command a higher price, but they may also be less desirable employees because of their perceived Beijinger ego and pride. By the same token, 
Gansu baomu may have "undesirable” regional hygiene habits and manners, but they are cheaper and have the added value of enhancing, rather than challenging, urban residents' sense of superiority. In comparison to Beijing baomu, Gansu baomu, like water that is "bottled at the source," can be seen to be, as Yan Hairong puts it, "fresher," more "unknowing" and "malleable," and "uncontaminated" by the city. ${ }^{51}$

\section{Conclusion}

Since the I980s, an important element in official rhetoric on suzhi (quality) has been the call to improve the overall suzhi of the nation and, in particular, to educate, "civilize," discipline, and "modernize" social groups such as rural migrants, so that they too will eventually join the ranks of a growing middle class. However, in this essay I have demonstrated that of equal political importance is the definition, branding, and classification of people according to their place of origin in terms of the suzhi that supposedly inheres in the bodies from that particular place. To be sure, there are some ruralites - including residents of small towns and cities - who have made it rich and are able to buy an urban hukou and with their newfound wealth are now pursuing a high standard of living in the city. On the other hand, the forbiddingly high cost of gaining an urban hukou and the default association of ruralites with low suzhi do work in tandem to ensure that place-based branding practices effectively keep the rurality of rural migrants firmly in place; most such migrants continue to be disqualified from membership in the jealously guarded middle class. Contrary to the officially stated intention of the suzhi improvement project, suzhi discourse generally inhibits rather than facilitates upward mobility.

While neither class nor rural-urban difference can singlehandedly account for the hegemonic narrative about the lack of suzhi among rural migrant workers, both are important aspects that are not mutually exclusive or contradictory. The class analysis framework would become much more enabling if it were to take on a spatial dimension. Social stratification, economic disparity, and class difference can be the product, as well as the consequence, of spatial difference and inequality. Similarly, the spatial framework needs to be able to account for more nuanced and complex meanings 
of "urban" and "rural." The interface between class on the one hand, and place and space on the other, is made productive and demonstrable through the most intimate yet controlled physical interaction between the migrant laborer and the urban, middle-class clients he or she serves. In the routine practice of marking the employer-versus-employee difference, the mobile migrant body has been reterritorialized, marked with ethnicity, proved to be inferior, and found wanting as far as suzhi is concerned. Mobility, in other words, does not help the migrant shed rurality and gain suzhi; instead, he or she becomes "rural," an "outsider," and lacking in suzhi once mobility is obtained. In other words, suzhi discourse both marks and disguises class difference. "Lacking suzhi" has become a convenient and euphemistic way of calling someone "lower-class," whereas "middle-class" by default denotes the possession of "high suzhi."

It is in this specific sense that I understand the corporeal politics of suzhi. What helps explain the subordination, peripheralization, and exploitation of the rural migrant by her urban employer is not just class difference or rural-urban duality — though both are important to consider — but the numerous ways in which the migrant body is made to take on a subaltern and outsider status. The scale of place deployed to construct the subalternity of the migrant may vary, may range from provincial to regional, but it is always the body — the smallest-scale place — on which such subalternity is (re)inscribed. Like anyone's body, the migrant body has both a physical and semiotic dimension. Integral to the process of naturalization, by which the suzhi deficiency of the migrant is made to become "commonsensical" and unquestionable, is the continuous and repetitious deployment of the body. The "migrant = suzhi" deficiency equation is thus established, and through repeated use, its logic is naturalized and taken for granted.

\section{Notes}

I would like to thank Tamara Jacka and Gary Sigley for their detailed editorial suggestions.

I. Sun Wanning, "Anhui Baomu in Shanghai: Gender, Class, and a Sense of Place," in Locating China: Space, Place and Popular Culture, ed. Jing Wang (London: Routledge, 2005), I7 I-89. 
2. Yan Hairong, "Neoliberal Governmentality and Neohumanism: Organising Suzhi/Value Flow through Labor Recruitment Networks," Cultural Anthropology i8 (2003): 493-523. 3. Ibid., 498.

4. Yan Hairong, "Self-Development of Migrant Women and the Production of Suzhi (Quality) as Surplus Value," in Everyday Modernity in China, ed. Madeleine Yue Dong and Joshua Goldstein (Seattle: University of Washington Press, 2006), 227-59.

5. Ann Anagnost, "The Corporeal Politics of Quality (Suzhi)," Public Culture I6 (2004): I89208.

6. Baomu in Chinese means "maid" and, like the word maid in English, is distinctively female. The fact that baomu are often addressed by their urban employers as ayi (aunty) is further lexical evidence of the gender-specificity of this type of work. I have opted to use the most commonly used word, baomu, in my essay despite these associations. I am, of course, aware of the potentially derogatory — gender and class — connotations of the term. However, it is also my impression that most people — including urban residents and migrant workers use the term without intending to insult, as, again, in the use of the word maid. The Chinese Ministry of Labor prefers to describe those engaged in domestic work as jiazheng fuwu yuan (domestic worker). While the official term is gender-neutral, it is not free from a political agenda of its own and is ironically but unintentionally complicit with certain feminist positions on this matter.

7. Tamara Jacka, Rural Women in Urban China: Gender, Migration, and Social Change (Armonk, NY: M. E. Sharpe, 2006), ro8.

8. Emily Honig, Creating Chinese Ethnicity: Subei People in Shanghai, 1850-1980 (New Haven: Yale University Press, 1992).

9. For a discussion of Hui (i.e., Anhui) merchants and Hui culture, see Wanning Sun, "Discourse of Poverty: Weakness, Potential and Provincial Identity in Anhui," in Rethinking China's Provinces, ed. John Fitzgerald (London: Routledge, 2002), 153-78.

Io. Fei-ling Wang, Organizing through Division and Exclusion: China's Hukou System (Stanford, CA: Stanford University Press, 2005), xii.

I I. Many scholars have considered how the hukou system discriminates against rural migrants. See, for instance, Wang, Organizing through Division and Exclusion; Li Zhang, Strangers in the City: Reconfigurations of Space, Power, and Social Networks within China's Floating Population (Stanford, CA: Stanford University Press, 200I); Dorothy Solinger, Contesting Citizenship in Urban China: Peasant Migration, the State, and the Logic of the Market (Berkeley: University of California Press, 1999).

I2. Wang, Organizing through Division and Exclusion, I80.

13. Interview with baomu employer, July 2005, Beijing.

I4. Wu Wenjie, "Baomu, guzhu 'chengjiao' za zhenme nan?” ("Why Is It So Hard for the Baomu and Employer to Reach an Agreement?"), Jingji ribao (Economic Daily), April I8, 2005. 
I5. This is not the place to talk at length about the contrast between the "abject" and the "sublime" body. Suffice it to say that such a contrast is drawn by Julia Kristeva in her work Powers of Horror: An Essay on Abjection, trans. Leon S. Roudiez (New York: Columbia University Press, 1982), especially in chap. I, "Approaching Abjection.” In this highly influential work, Kristeva observes that the abject body is where the boundaries of the body are transgressed and the internal becomes external. Mouth, nose, ears, eyes, anus, and vagina are all sites where the outside and the internal merge. Bodily fluids — blood, urine, tears, saliva, and feces - become repellent to us when they cross the boundary of the skin. Outside the body, bodily fluids are divorced from their owner's body. The search for a sublime body and denial of basic bodily functions is particularly symptomatic of Western culture. However, according to Kristeva, the sublime body is impossible, as abjection is a fact of being alive.

I6. Ngai Pun, Made in China: Factory Workers in a Global Workplace (Durham, NC: Duke University Press, 2005).

17. Chinese Ministry of Labor and Social Security, Jiazheng fuwuyuan shouce (A Handbookfor Domestic Workers) (Beijing: Chinese Ministry of Labor and Social Security Press, 20oo).

I8. Ibid., 5 .

19. Louisa Schein, "Negotiating Scale: Miao Women at a Distance," in Translocal China, ed. Tim Oakes and Louisa Schein (London: Routledge, 2006), 213-37.

2o. Ibid.

2r. See "Henan Anhui ji mian shi, Shenzhen mo qiye zhaogong guanggao re zhengyi" ("Henan and Anhui Applicants Need Not Apply: Shenzhen's Company Job Ad Becomes Controversial”), from www.people.com.cn (accessed June 2005).

22. See "Qishi Henan re an wuyue kaishen, kai quanguo xianhe" ("Legal Case against Discrimination of Henan People Due to Start in May - The First of This Kind in China"), Lanling (Blue Bell) 22 (2005): 70.

23. Yan Hairong, "Spectralization of the Rural: Reinterpreting the Labour Mobility of Rural Young Women in Post-Mao China," American Ethnologist 30, no. 4 (2003): 578-96.

24. Pun, Made in China, 50.

25. Interview with Zhang Xianmin, June 2005, Beijing.

26. Feng Xiaoshuang, "Zhuanxin shehui zhong baomu he guzhu de guanxi" ("The MaidEmployer Relationship in the Transitional Society"), in Zhuan xin zhong de Zhongguo funü (Chinese Women in Transitional Society), ed. Meng Xianfan (Beijing: China Academy of Social Science Press, 2004), 34 .

27. Ibid.

28. Xie Lihua is deputy editor-in-chief of China Women's Daily and founder of the Migrant Women's Club, a nongovernmental organization (NGO) in Beijing dedicated to providing legal and emotional support to rural women. The interview was conducted in Beijing in July 2005 . 
29. Interview with Zhang, July 2005.

30. Interview with Stella Xing, June 2005, Beijing.

3I. Feng, "Zhuanxin shehui zhong baomu he guzhu de guanxi," 34.

32. Conversations with Xie, June and July 2005, Beijing.

33. Interview with Shen, July 2005, Beijing.

34. Peters John Durham, "Exile, Nomadism, and the Diaspora: The Stakes of Mobility in the Western Canon," in Home, Exile, Homeland, ed. Hamid Naficy (New York: Routledge, I999), I7-44.

35. Interview with Sylvia Xu, June 200I, Shanghai.

36. Interview with Ge, March 2003, Shanghai.

37. Zhang, Strangers in the City.

38. See Li Haixia, "Baomu Chuan Mei Zi Jin Jing Zao Feng Qiang” ("Sichuan baomu are Snatched Up by Prospective Employers upon Arrival in Beijing”), www.xinhuanet.com (accessed February 2004).

39. Tim Oakes and Louisa Schein, “Translocal China: An Introduction,” in Translocal China: Linkages, Identities, and the Reimagining of Space, ed. Tim Oakes and Louisa Schein (London: Routledge, 2006), 28.

4o. Ibid.

4I. Interview with $\mathrm{Xu}$ Xiying, June 2005, Beijing.

42. See Li Lei, “Zongshu: Chong qiang shou dao tang shou chuan mei zi baomu za la," ("Summary: From High Demand to Reject: What Happens to Sichuan Mei?") Huaxi dushi bao (Western China Metropolitan Daily), www.scol.com.cn (accessed June 2005).

43. See "Di yi kou: 2004 de chang xian huo dong" ("Have a Bite: Tasting Freshness in 2004") (anon.), Jingpin Gouwu Zhinan (The Elite Shoppers Guide to Luxury Goods), www.csonline .com.cn (accessed June 2005).

44. According to a 2006 work report produced by Beijing's March 8th Domestic Service Center, the biggest and most established center of this kind in Beijing, as many as 95 percent of the domestic workers registered with the center are from outside Beijing, from mostly rural areas. "Beijing shi sanba fuwu zhongxin jiazheng fuwuyuan guanli fuwuyu weiquan gongzuo qingkuang huibao" ("Report on the Beijing March 8th Domestic Service Center's Performance on Management and Rights Protection)

45. Liu Yida's I998 statistics indicate that there were around one hundred local Beijing residents working as baomu.

46. The survey results are recorded in Liu Yida, Cangsheng Fanjing: Beijing Yan (Ordinary People Extraordinary Times: The Eye of Beijing) (Beijing: Zhongguo shehui chubanshe, I998).

47. Ibid.

48. Interviews with Zhang, July 2005 and September 2006.

49. Interview with Stella Xing, July 2005. 
50. Lenore Lyons, "Embodying Transnationalism: The Making of the Maid," in Corporeal Inscriptions: Representations of the Body in Cultural and Literary Texts and Practices, ed. Edyta Lorek-Jezinska and Katarzyna Wieckowska (Torun: Nicolas Copernicus University, 2005), I 7 I-85.

5I. Yan, "Spectralization of the Rural." 
wealth are now pursuing a high standard of living in the city. On the other hand, the forbiddingly high cost of gaining an urban hukou and the default association of ruralites with low suzhi do work in tandem to ensure that place-based branding practices effectively keep the rurality of rural migrants firmly in place; most such migrants continue to be disqualified from membership in the jealously guarded middle class. Contrary to the officially stated intention of the suzhi improvement project, suzhi discourse generally inhibits rather than facilitates upward mobility.

While neither class nor rural-urban difference can singlehandedly account for the hegemonic narrative about the lack of suzhi among rural migrant workers, both are important aspects that are not mutually exclusive or contradictory. The class analysis framework would become much more enabling if it were to take on a spatial dimension. Social stratification, economic disparity, and class difference can be the product, as well as the consequence, of spatial difference and inequality. Similarly, the spatial framework needs to be able to account for more nuanced and complex meanings [End Page 637] of "urban" and "rural." The interface between class on the one hand, and place and space on the other, is made productive and demonstrable through the most intimate yet controlled physical interaction between the migrant laborer and the urban, middle-class clients he or she serves. In the routine practice of marking the employer-versus-employee difference, the mobile migrant body has been reterritorialized, marked with ethnicity, proved to be inferior, and found wanting as far as suzhi is concerned. Mobility, in other words, does not help the migrant shed rurality and gain suzhi; instead, he or she becomes "rural," an "outsider," and lacking in suzhi once mobility is obtained. In other words, suzhi discourse both marks and disguises class difference. "Lacking suzhi" has become a convenient and euphemistic way of calling someone "lower-class," whereas "middle-class" by default denotes the possession of "high suzhi."

It is in this specific sense that I understand the corporeal politics of suzhi. What helps explain the subordination, peripheralization, and exploitation of the rural migrant by her urban employer is not just class difference or rural-urban duality — though both are important to consider - but the numerous ways in which the migrant body is made to take on a subaltern and outsider status. The scale of place deployed to construct the subalternity of the migrant may vary, may range from provincial to regional, but it is always the body —-the smallest-scale place —on which such subalternity is (re)inscribed. Like anyone's body, the migrant body has both a physical and semiotic dimension. Integral to the process of naturalization, by which the suzhi deficiency of the migrant is made to become "commonsensical" and unquestionable, is the continuous and repetitious deployment of the body. The "migrant = suzhi" deficiency equation is thus established, and through repeated use, its logic is naturalized and taken for granted.

$\underline{\text { Wanning Sun }}$

Wanning Sun is Professor of Chinese Media and Cultural Studies at China Research Centre, University of Technology Sydney (UTS), Australia. Her most recent publication is Maid in China: Media, Morality, and the Cultural Politics of Boundaries (2009).

\section{Acknow ledgement}

I would like to thank Tamara Jacka and Gary Sigley for their detailed editorial suggestions.

\section{Notes}

1. Sun Wanning, "Anhui Baomu in Shanghai: Gender, Class, and a Sense of Place," in Locating China: Space, Place and Popular Culture, ed. Jing Wang (London: Routledge, 2005), 171-89. [End Page 638]

2. Yan Hairong, "Neoliberal Governmentality and Neohumanism: Organising Suzhi/Value Flow through Labor Recruitment Networks," Cultural Anthropology 18 (2003): 493-523.

3. Ibid., 498.

4. Yan Hairong, "Self-Development of Migrant Women and the Production of Suzhi (Quality) as Surplus Value," in Everyday Modernity in China, ed. Madeleine Yue Dong and Joshua Goldstein (Seattle: University of Washington Press, 2006), 227-59.

5. Ann Anagnost, "The Corporeal Politics of Quality (Suzhi)," Public Culture 16 (2004): 189-208.

6. Baomu in Chinese means "maid" and, like the word maid in English, is distinctively female. The fact that baomu are often addressed by their urban employers as ayi (aunty) is further lexical evidence of the gender-specificity of this type of work. I have opted to use the most commonly used word, baomu, in my essay despite these associations. I am, of course, aware of the potentially derogatory — gender and class — connotations of the term. However, it is also my impression that most people —including urban residents and migrant workers — use the term without intending to insult, as, again, in the use of the word maid. The Chinese Ministry of Labor prefers to describe those engaged in domestic work as jiazheng fuwu yuan (domestic worker). While the official term is gender-neutral, it is not free from a political agenda of its own and is ironically but unintentionally complicit with certain feminist positions on this matter.

7. Tamara Jacka, Rural Women in Urban China: Gender, Migration, and Social Change (Armonk, NY: M. E. Sharpe, 2006$), 108$.

8. Emily Honig, Creating Chinese Ethnicity: Subei People in Shanghai, 1850-1980 (New Haven: Yale University Press, 1992).

9. For a discussion of Hui (i.e., Anhui) merchants and Hui culture, see Wanning Sun, "Discourse of Poverty: Weakness, Potential and Provincial Identity in Anhui," in Rethinking China's Provinces, ed. John Fitzgerald (London: Routledge, 2002), 153-78.

10. Fei-ling Wang, Organizing through Division and Exclusion: China's Hukou System (Stanford, CA: Stanford University Press, 2005), xii.

11. Many scholars have considered how the hukou system discriminates against rural migrants. See, for instance, Wang, Organizing through Division and Exclusion; Li Zhang, Strangers in the City: Reconfigurations of Space, Power, and Social Networks within China's Floating Population (Stanford, CA: Stanford University Press, 2001); Dorothy Solinger, Contesting Citizenship in Urban China: Peasant Migration, the State, and the Logic of the Market (Berkeley: University of California Press, 1999).

12. Wang, Organizing through Division and Exclusion, 180.

13. Interview with baomu employer, July 2005, Beijing.

14. Wu Wenjie, "Baomu, guzhu 'chengjiao' za zhenme nan?" ("Why Is It So Hard for the Baomu and Employer to Reach an Agreement?"), Jingji ribao (Economic Daily), April 18, 2005. [End Page 639]

15. This is not the place to talk at length about the contrast between the "abject" and the "sublime" body. Suffice it to say that such a contrast is 


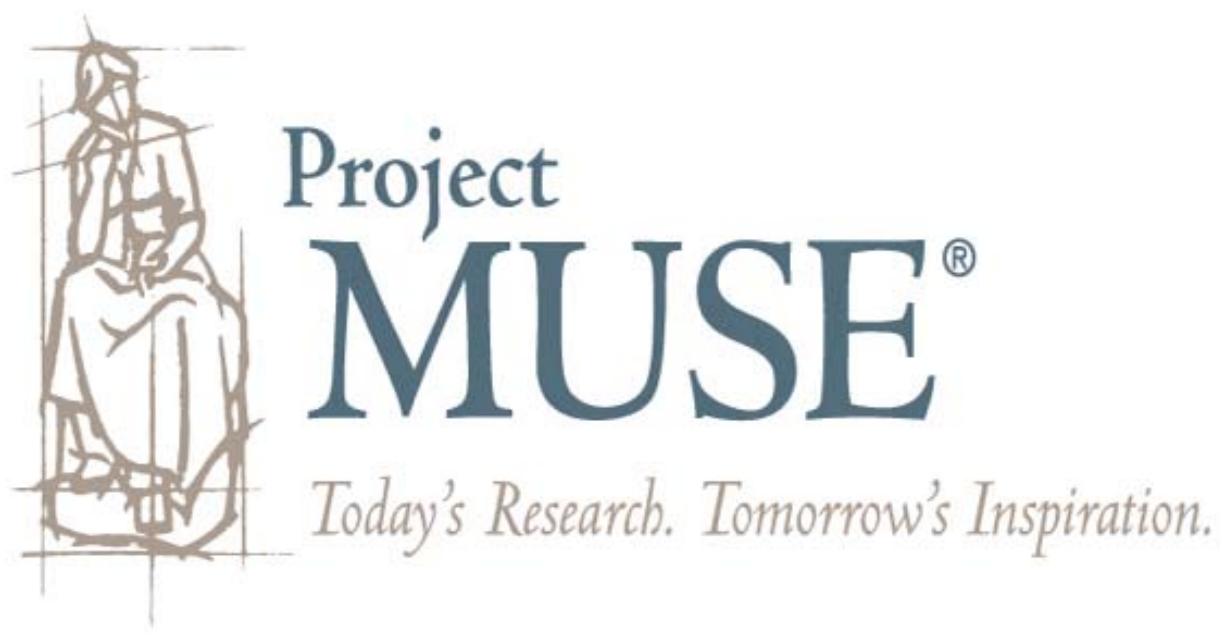

